\title{
Interleukin-25 and eosinophils progenitor cell mobilization in allergic asthma
}

\author{
Wei Tang ${ }^{1,2}$, Steven G. Smith¹, Wei Du², Akash Gugilla1, Juan Du², John Paul Oliveria' ${ }^{1}$ Karen Howie', \\ Brittany M. Salter', Gail M. Gauvreau', Paul M. O'Byrne ${ }^{1}$ and Roma Sehmi ${ }^{\text {* }}$
}

\begin{abstract}
Background: Eosinophil-lineage committed progenitor cells (EoP) migrate from the bone marrow and differentiate locally to provide an ongoing source of mature eosinophils in asthmatic inflammatory responses in the airways. Sputum levels of EoP are increased in asthmatics compared to normal controls suggesting an exaggerated eosinophilopoietic environment in the airways. Understanding what factors promote EoP traffic to the airways is important to understand the diathesis of asthma pathology. Interleukin (IL)-25, is an epithelial-derived cytokine that promotes type 2 inflammatory responses. We have previously shown that levels of IL-25 and expression of the IL-25 receptor (IL-17RA and IL-17RB) on mature eosinophils are greater in allergic asthmatics compared to atopic non-asthmatics and non-atopic normal controls. In addition, these levels were increased significantly increased following allergen inhalation challenge and physiologically relevant levels of IL-25 stimulated eosinophil degranulation, intracellular IL-5 and IL-13 expression and primed migration to eotaxin. The current study, examined the role of IL-25 on allergen-induced trafficking of EoP in atopic asthmatics.
\end{abstract}

Methods: Asthmatics $(n=14)$ who developed allergen-induced early and late responses were enrolled in the study. Blood was collected at pre- and $24 \mathrm{~h}$ post-challenge. At each time point, surface expression of IL-17RA and IL-17RB on EoP was evaluated by flow cytometry. Migration assays examined the effect of IL-25 on EoP chemotactic responses, in vitro. In addition, IL-25 knockout ovalbumin (OVA) sensitized and challenged mice were studied to evaluate in vivo mobilization effects of IL-25 on newly formed EoP and mature eosinophils.

Results: There was a significant increase in numbers of blood EoP expressing IL-17RB, $24 \mathrm{~h}$ post-allergen inhalation challenge in allergic asthmatics. Pre-exposure to IL-25 primed the migrational responsiveness of EoP to stromal cellderived factor 1a. In OVA-sensitized mice, knocking out IL-25 significantly alleviated OVA-induced eosinophil infiltration in the airway and newly formed eosinophils were reduced in the lung.

Conclusions: The findings of this study indicate a potential role for IL-25 in allergen-induced trafficking of EoP to the airways and local differentiation promoting tissue eosiniophilia in asthmatic responses.

Keywords: Asthma, Allergen challenge, Eosinophils progenitor, IL-25, IL-25 receptors, BrdU, CD34

\section{Background}

Asthma is a chronic disease of the airways characterized by reversible airflow obstruction, airway inflammation and airway hypperesponsiveness. Tissue eosinophilia and type 2 cytokine producing cells including T-helper (Th) 2 cells and group 2 innate lymphoid cells, are the

\footnotetext{
*Correspondence: sehmir@mcmaster.ca

1 Division of Respirology, Department of Medicine, McMaster University, Hamilton, ON L6M 1A6, Canada

Full list of author information is available at the end of the article
}

predominant components of the airway inflammatory cell infiltrate in subjects with allergic asthma [1].

Interleukin-25 (IL-25; IL-17E) is a pro-inflammatory cytokine that belongs to the IL-17 cytokine family and, unlike other members of the IL-17 family, plays a pivotal role in the maintenance of type 2 immune responses [2]. IL-25 has been shown to directly activate eosinophils, by up-regulation of the adhesion molecule ICAM-1, stimulate the release of pro-inflammatory chemokines such as monocyte chemoattractant protein-1, IL-8, macrophage 
inflammatory protein-1 and IL-6, as well as delay apoptosis [3, 4]. The IL-25 receptor consists of two subunits, IL-17RA (the signaling sub-unit) and IL-17RB (the specific cytokine binding subunit) that form the functional heterodimeric receptor, IL-17RA/RB [5]. In a previous baseline cross-sectional study, we have shown significantly increased expression of IL-17RA and IL-17RB on mature eosinophils and plasma levels of IL-25 in asymptomatic mild allergic asthmatics compared with atopic non-asthmatics and non-atopic normal subjects [6]. In addition, we reported significant increases in plasma levels of IL-25 and intracellular IL-25 eosinophil levels, as well as IL-17RA/RB and IL-17RB receptor expression on mature eosinophils, $24 \mathrm{~h}$ following allergen-inhalation challenge in allergic asthmatics [7]. Furthermore in vitro experiments showed that at physiologically relevant concentrations, IL-25 stimulated eosinophil degranulation and primed the migrational responses of mature eosinophils.

A considerable body of evidence supports the view that in allergic asthma, eosinophil-lineage committed progenitor cells (EoP) traffic from the bone marrow to the lungs via the peripheral circulation and that the local tissuedriven differentiation of these cells may contribute to the development and maintenance of tissue eosinophilia [8]. The effect of IL- 25 on the traffic of bone marrow-derived hemopoietic progenitor cells (HPC) and more specifically eosinophil-lineage commmited progenitor cells (EoP) to the lungs in allergic asthmatic responses has not been reported to date.

In this study, we examined IL-25 and IL-25R expression on EoP in asthmatic subjects following allergen-inhalation challenge. In addition, we employed an OVAsensitized mouse model to investigate whether traffic of mature eosinophils and newly formed eosinophils to the site of inflammation was influenced by IL- 25 .

\section{Methods}

\section{Study design}

Fourteen subjects with mild allergic asthma, aged between 19 and 52 years, were enrolled in the study. All volunteers were atopic with one or more positive skin prick tests; a forced expired volume in $1 \mathrm{~s}\left(\mathrm{FEV}_{1}\right)$ greater or equal to $70 \%$ of predicted; and dual airway responses to inhaled allergen as determined by a fall in $\mathrm{FEV}_{1} \geq 15 \%$ within the first $2 \mathrm{~h}$, followed by second fall in $\mathrm{FEV}_{1}$ between 3 and $7 \mathrm{~h}$ after allergen inhalation challenge (Table 1). All subjects were steroid naïve and only intermittently used $\beta_{2}$-agonists. Subjects attended the laboratory for three consecutive visits. On visit 1 (day 1), a medical history and physical examination were performed and subjects underwent a skin prick test, spirometry, methacholine inhalation challenge. On visit 2 (day
Table 1 Baseline subject characteristics

\begin{tabular}{lllcc}
\hline Sex & Age & Ag inhaled & $\begin{array}{l}\text { \%FEV1 } \\
\text { (\%predicted) }\end{array}$ & $\begin{array}{c}\text { PBaseline } \\
\mathbf{P C}_{\mathbf{2 0}} \text { (mg/ml) }\end{array}$ \\
\hline M & 19 & Cat & 81 & 0.31 \\
M & 25 & HDM & 114 & 10.31 \\
F & 19 & Cat & 117 & 20.80 \\
F & 49 & HDM & 97 & 1.07 \\
M & 44 & Grass & 73 & 16.00 \\
F & 41 & Ragweed & 94 & 0.83 \\
F & 47 & Cat & 90 & 0.60 \\
F & 20 & Tree & 92 & 3.19 \\
M & 52 & HDM & 100 & 6.99 \\
M & 27 & Ragweed & 97 & 2.71 \\
F & 21 & Horse & 98 & 16.00 \\
F & 19 & Ragweed & 80 & 5.82 \\
M & 49 & HDM & 90 & 16.00 \\
F & 24 & HDM & 116 & 0.38 \\
F & 25 & HDM & 108 & 15.48 \\
\hline
\end{tabular}

Subject characteristics: all subjects were skin prick test positive; had a forced expired volume in $1 \mathrm{~s}$ (FEV1) $\geq 70 \%$ predicted; $\mathrm{FEV}_{1}$ - forced expiratory volume in $1 \mathrm{~s}$; all patients $P C_{20}$ - provocative concentration of methacholine causing a $20 \%$ drop in $\mathrm{FEV}_{1}$; HDM house dust mite; $\mathrm{Ag}$ allergen

2), subjects underwent allergen inhalation challenge and spirometry was measured hourly up to $7 \mathrm{~h}$ post-challenge. At Visit 3 (day 3), spirometry and methacholine challenge was performed $24 \mathrm{~h}$ after inhalation challenge. Flow cytometric assessments were performed on blood samples collected before and $24 \mathrm{~h}$ post-allergen challenge. All subjects gave written informed consent, and the study was approved by the Hamilton Health Science Research Ethics Board (HIREB \# 12-583).

\section{Allergen inhalation challenge}

Allergen inhalation was performed as previously described [9]. The allergen producing the largest diameter skin wheel was diluted in saline for inhalation. The concentration of allergen required to achieve a $20 \%$ decrease in $\mathrm{FEV}_{1}$ (the allergen $\mathrm{PC}_{20}$ ) was predicted using the methacholine $\mathrm{PC}_{20}$ and the titration of allergen determined from the skin prick test. The early asthmatic response (EAR) was recorded as the greatest fall in $\mathrm{FEV}_{1}$ between 0 and $2 \mathrm{~h}$ after allergen inhalation, whereas the greatest drop in $\mathrm{FEV}_{1}$ between 3 and $7 \mathrm{~h}$ was recorded as the late asthmatic response (LAR) as previously described [9].

\section{Cell preparation and Immunofluorescence staining}

For identifying $\mathrm{CD} 34^{+}$hemopoietic progenitor cells, $20 \mathrm{~mL}$ heparinized venous blood was diluted with McCoys 5A (Invitrogen, USA), then layered on Lymphoprep (Axis-Shield, USA) and centrifuged (2200 rpm, 
$20 \mathrm{~min}$ ). Mononuclear cells were removed and washed with McCoy's 5A (centrifugation at $1500 \mathrm{rpm}$ for $10 \mathrm{~min}$ at $4{ }^{\circ} \mathrm{C}$ ) and re-suspended in FACS buffer, then immunostained with CD34-Alexa Fluor 700, CD45-Pacific Blue, CD125-APC, IL17RA-FITC and IL17RB-PE or corresponding isotype controls (BD Bioscience and $\mathrm{R} \& \mathrm{D}$ systems). Cells were incubated for $30 \mathrm{~min}$ at $4{ }^{\circ} \mathrm{C}$ then washed with FACS buffer and fixed in 1\% PFA prior to flow cytometric acquisition.

\section{Flow cytometry acquisition}

Data were acquired using a 15-color LSR II flow cytometer equipped with 3 lasers (Becton-Dickinson Instrument Systems) with FACSDiva software program (Becton-Dickinson Biosciences). Following acquisition of 300,000 events, data analyses were performed using FlowJo software version 9.3.2. (Tree Star Inc.) to enumerate IL-25 receptor components expression; for gating strategy details see Additional file 1: Fig. S1 for hemopoietic progenitor cells (HPC; CD $34^{\text {high }} \mathrm{CD} 45^{\text {dull }}$ ) and eosinophil-lineage committed progenitor cells (EoP; $\mathrm{CD} 34^{\text {high }} \mathrm{CD} 45^{\text {dull }} \mathrm{CD} 125^{\text {high }}$ ) as previously described in detail [10].

\section{Progenitor cell migration-trans well migration assay}

The migrational response of progenitors was assessed in transwell chambers (24-well cell clusters, $6.5 \mathrm{~mm}$ Transwell ${ }^{\circledR}$ with $5 \mu \mathrm{m}$ pore polycarbonate membrane insert filters; Corning Costar, NY, USA) as previously described [10]. Briefly, peripheral blood mononuclear cells isolated, as described above, were depleted by adherence to plastic $\left(2 \mathrm{~h}, 5 \% \mathrm{CO} 2\right.$ and $\left.37{ }^{\circ} \mathrm{C}\right)$ and $\mathrm{CD} 34^{+}$ cells enriched by positive selection using MACS immunomagnetic beads (Miltenyi Biotec, CA, USA). Cell purity of $\mathrm{CD}_{3} 4^{+}$cells was $>95 \%$, viability $>90 \%$. The chemoattractant, SDF-1 (CXCL12; $10 \mathrm{ng} / \mathrm{mL}$; R\&D Systems) or diluent (IMDM plus 10\% FBS) was loaded into the lower well and $\mathrm{CD} 34^{+}$cells $\left(5 \times 10^{4}\right)$ were added to the upper transwell inserts. Cells in the lower well (representing migrated responding cells) were immunostained as HPC $\left(\mathrm{CD} 34^{+} \mathrm{CD} 45^{+}\right)$or EoP $\left(\mathrm{CD} 45^{+} \mathrm{CD} 34^{+} \mathrm{CD} 125^{+}\right)$ and enumerated by flow cytometry, as described above. Migrated cells were expressed as a percentage of the total cells added to the top transwell. Cells were pre-incubated with IL-25 (R\&D Systems) for $18 \mathrm{~h}\left(37{ }^{\circ} \mathrm{C}, 5 \% \mathrm{CO}_{2}\right)$ prior to the migration assay.

\section{OVA sensitized mice}

Wild type C57BL/6 mice were purchased from Shanghai SLAC laboratory Co., Ltd. (Shanghai, China). IL-25 knockout mice on the same background were purchased from Qinghua University animal center (Beijin, China). Mice were aged between 6 and 8 weeks-old, weighing between 20 and $22 \mathrm{~g}$, and were housed at $18-25{ }^{\circ} \mathrm{C}$, humidity $50-60 \%, 0.03 \% \mathrm{CO}_{2}, 12 / 12 \mathrm{~h}$ light/dark cycle and food/water were available ad libitum and refreshed every 3 days. For both wild type and IL-25KO mice, the sensitized animals (OVA sensitized and OVA challenged; $\mathrm{n}=6$ ) received an intraperitoneal injection of $100 \mu \mathrm{g}$ ovalbumin (OVA; Sigma Aldrich; Merck KGaA) and $2 \mathrm{mg}$ alum (Sigma Aldrich; Merck KGaA) in PBS on days 0, 7 and 14. On days 25, 26 and 27, the mice were challenge with aerosolized 1\% OVA in PBS for $30 \mathrm{~min}$. For both wild type and IL-25KO mice, Sham control mice (Sham sensitized and Sham challenged, $\mathrm{n}=6$ ) received PBS intraperitoneally with alum on days 0,7 and 14, and were challenged with aerosolized PBS on days 25,26 and 27. BrdU (1 mg) was given by intraperitoneal injection twice per day, on days 25 and 27, 30 min prior to challenge with OVA as previously described $[11,12]$.

\section{Bronchoalveolar lavage fluid (BALF), blood and bone marrow sampling}

BALF collection was performed $24 \mathrm{~h}$ after the final OVA or PBS challenge. Lungs were lavaged with $1 \mathrm{~mL}$ PBS through the trachea and BALF was collected. Blood (0.5$0.8 \mathrm{~mL}$ ) was drawn prior to BALF collection into heparin from each mouse. Bone marrow was harvested from the femur and tibia into heparin as previously described [12]. Smears of blood and bone marrow samples were made to perform eosinophil counts following standard staining with hematoxolin and eosin.

\section{Measurement of eosinophil number in BALF}

Cells were seeded in PBS medium (Beyotime Institute of Biotechnology, Haimen, China) at $1 \times 10^{5}$ cells $/ \mathrm{mL}$ and stained with Fast Wright and Giemsa Stain kit (Nanjing Jiancheng Technology Co., Ltd., Nanjing, China), according to manufacturer's protocol. Eosinophils were counted with a light microscope and expressed as percent eosinophils.

\section{Inflammatory index measurement}

The lung inflammation index score after OVA or diluent challenge was measured as previously described [13]. The index is: 0 equals no inflammatory infiltration; 1 equals a minimal inflammatory cell infiltration; 2 equals a layer of inflammatory cells annular infiltration; 3 equals 2-4 layers of inflammatory cell ring infiltration; 4 equals more than 4 layers of inflammatory cells annular infiltration.

\section{Immunohistochemistry (IHC) semi-quantitative analysis}

The expression levels of BrdU in lung tissues were quantified by Image-Pro Plus 6.0, expressed as mean optical density (OD), which equals intensity of optical density divided by area of lung tissues observed under 
microscope $(400 \times)$. Newly produced eosinophils were identified as BrdU positive and eosin positive cells.

\section{Statistical analysis}

Statistical analysis was performed using GraphPad Prism5 software (GraphPad Software Inc.). This study is powered on sputum eosinophil progenitor cells in mild asthmatics, and changes $24 \mathrm{~h}$ post-allergen were the primary outcome. Assuming within subject variability from previously published data in mild asthmatics [9], the sample size required to detect the "minimal important differences" between baseline and $24 \mathrm{~h}$ post-allergen measurements was calculated. Based on repeated measures ANOVA analyses, using the sample size module of NCSS statistical package with $\beta=0.20$ (power $=80 \%$ ) and $\alpha=0.05$ (likelihood of type 1 error $=5 \%$ ) and a minimum important difference $=0.72, \mathrm{SD}=0.59$, the sample size is calculated to be $\mathrm{n}=14$. Normally distributed data are expressed as mean \pm SEM. The methacholine $\mathrm{PC}_{20}$ is expressed as geometric mean and geometric standard error of the mean (GSEM). For HPC and EoP IL-25 receptor expression and migration experiments, a repeated measures ANOVA was used. Post-hoc comparisons were performed using the Tukey's multiple comparison tests. $\mathrm{p}<0.05$ was considered significant for all analyses.

\section{Results}

Following allergen inhalation challenge, all asthmatic subjects developed an early and late bronchoconstrictor responses; the maximal early fall in $\mathrm{FEV}_{1}$ (within $0-2 \mathrm{~h}$ post-allergen) was $33.67+8.22 \%$ and the maximal late fall in $\mathrm{FEV}_{1}$ (3-7 $\mathrm{h}$ post-allergen inhalation) was $22.47+8.43 \%$ (Table 2). This was associated with a significant increase airway eosinophilia (Table 2) and total number of number of blood HPC and EoP (HPC: $1663 \pm 657$ vs. $723 \pm 244$ per $10^{6}$ WBC, $\mathrm{p}<0.01$; EoP: $1188 \pm 442$ vs. $519 \pm 140$ per $10^{6}$ WBC, $\left.\mathrm{p}<0.01\right) 24 \mathrm{~h}$ post-allergen compared to pre-allergen levels. Further phenotypic analyses of HPC and EoP demonstrated significant increases in expression of IL-25 specific binding sub-unit (IL-17RB), $24 \mathrm{~h}$ post-allergen compared to preallergen baseline levels (Fig. 1). In contrast, these changes were not observed for the signaling sub-unit IL-17RA or combined receptor complex IL-17RA/RB on either HPC or EoP (Fig. 1).

In pilot studies, we found that IL-25 over a wide concentration range $(0.1-1000 \mathrm{pg} / \mathrm{ml})$ has no effect on the migrational responses of EoP compared to diluent control, in vitro (data not shown). However, pre-incubation with IL-25 (optimal concentration $1 \mathrm{pg} / \mathrm{ml}$ ), compared to diluent, significantly enhanced the subsequent migrational response of both HPC and EoP to a sub-optimal
Table 2 Subject lung function and sputum

\begin{tabular}{ll}
\hline & Allergen challenge \\
\hline EAR $\left(\%\right.$ change in $\left.\mathrm{FEV}_{1}\right)$ & $-33.67 \pm 2.12^{\#}$ \\
LAR $\left(\%\right.$ change in $\left.\mathrm{FEV}_{1}\right)$ & $-24.47 \pm 1.77^{\#}$ \\
Methacoline $\mathrm{PC}_{20}(\mathrm{mg} / \mathrm{mL})$ & \\
Pre-Ag & $7.77 \pm 1.88$ \\
$24 \mathrm{~h}$ post-Ag & $2.20 \pm 0.51^{*}$ \\
Total sputum cells $\left(\times 10^{6} \mathrm{cells} / \mathrm{mL}\right)$ & $3.62 \pm 0.64$ \\
Pre-Ag & $6.59 \pm 1.27^{*}$ \\
$24 \mathrm{~h}$ Post-Ag & \\
Sputum eosinophils $(\%)$ & $4.68 \pm 1.63$ \\
Pre-Ag & $12.26 \pm 2.68^{*, \#}$ \\
$24 \mathrm{~h}$ Post-Ag & \\
Blood eosinophils (per $\left.10^{9} \mathrm{WBC}\right)$ & $38 \pm 6$ \\
Pre-Ag & $64 \pm 9^{*}$ \\
$24 \mathrm{~h}$ Post-Ag & \\
\hline
\end{tabular}

Data are presented as geometric mean \pm SEM. There was a significant difference the EAR and LAR \% change in FEV ${ }_{1}$, methacoline $\mathrm{PC}_{20}$, total sputum cells, and sputum and blood eosinophils post-allergen

$F E V_{1}$ forced expiratory volume in $1 \mathrm{~s} ; P C 20$ provocative concentration of methacholine causing a $20 \%$ drop in $\mathrm{FEV}_{1}, A g$ allergen, EAR early asthmatic response, $L A R$ late asthmatic response, WBC white blood cells, HPC hemopoietic progenitor cells, EOP eosinophil progenitors

${ }^{*} \mathrm{p}<0.05$ comparison to baseline and ${ }^{\#} \mathrm{p}<0.05$ comparison to diluent

concentration of SDF-1 $\alpha(10 \mathrm{ng} / \mathrm{ml})(\mathrm{HPC}: 64 \pm 13$ vs. $35 \pm 6$ and EoP: $73 \pm 8$ vs. $39 \pm 10$ respectively, $\mathrm{p}<0.0001$ ) (Fig. 2). Pre-treatment with an IL-25 neutralizing antibody (previously optimized at $2.4 \mathrm{ng} / \mathrm{ml}$ ) significantly inhibited the priming effect of IL- 25 on SDF- $1 \alpha$ stimulated migration of HPC and EoP (Fig. 2).

In IL-25 knock out (KO) mice that were OVA-sensitized, a partial but significant attenuation of airway inflammation following allergen -challenge was observed (Additional file 2: Fig. S2). The inflammatory index in the control mice compared to wild type OVA challenged and IL-25 KO OVA challenged mice were $0.50 \pm 0.51$ vs. $1.63 \pm 0.77$ vs $0.93 \pm 0.54$ respectively ( $\mathrm{p}<0.001$ for all comparisons to control mice) (Fig. 3). Furthermore, OVA challenge significantly increased the percentages of eosinophils in wild type compared to control mice in BALF $(7.83 \pm 4.84$ vs. $3.40 \pm 0.43 \%)$ and bone marrow samples (5.33 \pm 0.85 vs. $2.7 \pm 0.25 \%)$ (Fig. 4). Compared to the wild type mice, eosinophils levels were significantly attenuated in the OVA challenged IL-25 KO mice in BALF (7.83 \pm 4.84 , vs. $3.06 \pm 1.78 \%$, p < 0.01) (Fig. 4).

The proportion of BrdU + eosinophils expressed as a percentage of the total eosinophils in BAL and bone marrow was significantly reduced in OVA challenged IL-25 $\mathrm{KO}$ mice compared to wild type mice (BAL: $12.5 \pm 6.51$ vs. $51.7 \pm 7.56 \%$, p $<0.01$; bone marrow: $2.4 \pm 1.28$ vs. $69.1 \pm 6.11 \%, \mathrm{p}<0.001$ ) (Fig. 5). In the lungs, BrdU expression after OVA challenge was 

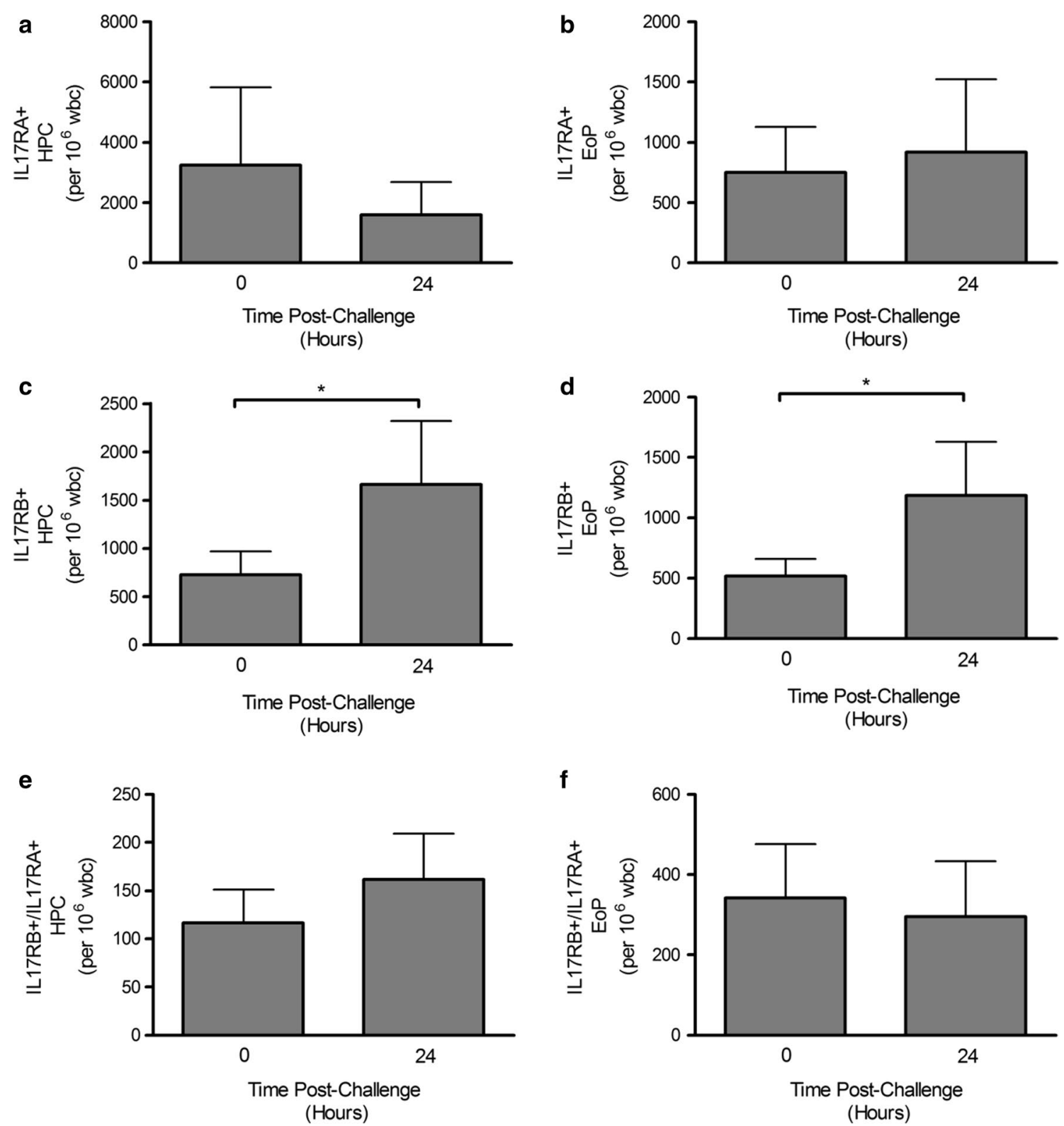

Fig. 1 Allergen-induced changes in IL-25 receptor expression on blood HPC and EoP. Expression of IL-17RA ${ }^{+}(\mathbf{a}, \mathbf{b})$, IL-17RB ${ }^{+}(\mathbf{c}, \mathbf{d})$ and IL-17RA/RB ${ }^{+}$ $(\mathbf{e}, \mathbf{f})$ in mild allergic asthmatics following allergen-inhalation challenge. There was a significant increase in the number of HPC and EoP expressing $\mathrm{IL}-17 \mathrm{RB}^{+} 24 \mathrm{~h}$ post-allergen inhalation challenge. Data are mean $\pm \mathrm{SEM}(\mathrm{n}=14)$

significantly decreased in IL-25 KO mice compared with wild type mice (mean density, $0.013 \pm 0.010 \mathrm{OD}$ vs. $0.020 \pm 0.013 \mathrm{OD} ; \mathrm{p}<0.01$ ), (Fig. 6).

\section{Discussion}

This study has demonstrated that following allergeninhalation challenge in allergic asthmatic subjects, IL$17 \mathrm{RB}$ is up-regulated on the surface of HPC, as well as EoP in the blood. In addition, IL-25 primes migrational responses of blood-derived HPC and EoP to the progenitor chemoattractant, SDF-1 $\alpha$. These findings suggest that in response to inhaled allergen, upregulation of IL-25 receptor binding sub-unit expression on EoP in peripheral blood may promote increased occupancy of IL-25 on its specific receptor and stimulate priming of migrational responsiveness, thereby facilitating the homing of eosinophil precursors to the airways. Furthermore, in OVA-sensitized mice, knocking out IL-25 significantly 

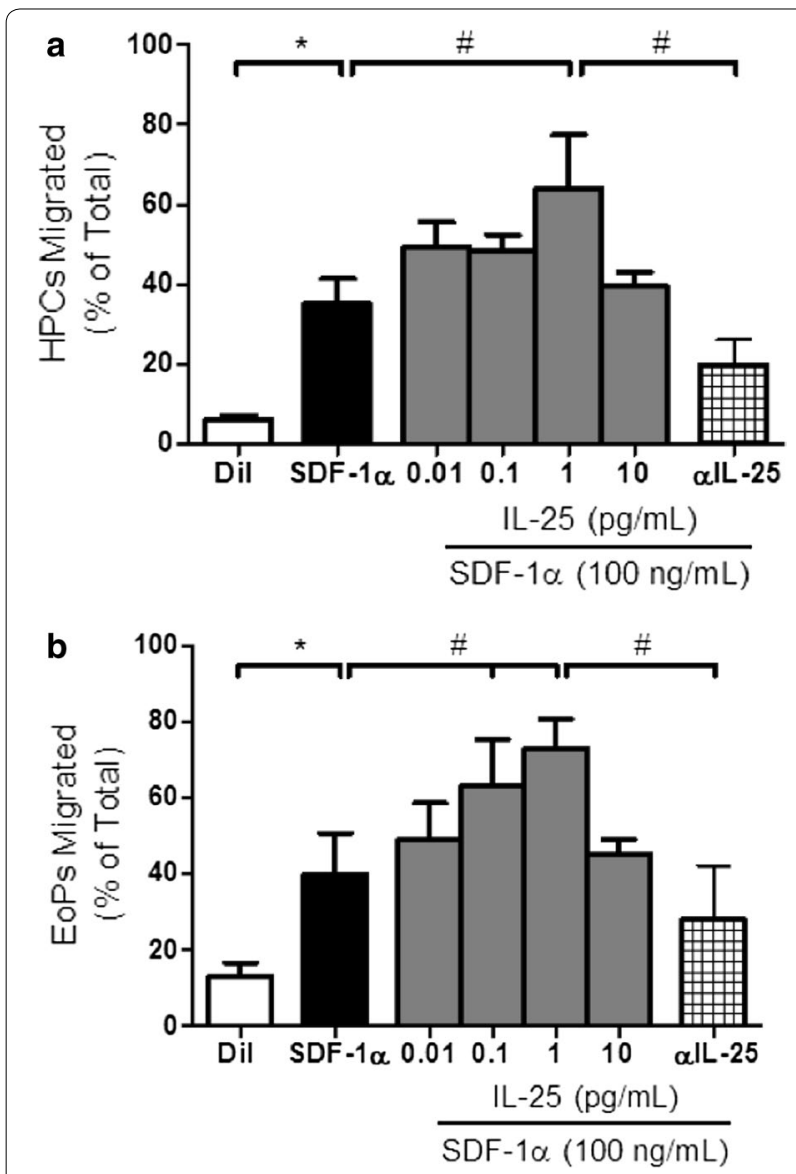

Fig. $2 \mathrm{IL}-25$ priming of (a) HPC and $\mathbf{b}$ EOP migration, in vitro. Preincubation overnight with IL-25 primed the migrational responsiveness of both HPC and EOP stimulated by SDF-1a. SDF-1a alone induced migration. Data are presented as mean $\pm \operatorname{SEM}(n=6)$ ( ${ }^{*} p<0.05$ comparison to diluent; ${ }^{*} p<0.05$ comparison to SDF-1a alone)

alleviated lung inflammation, airway eosinophil infiltration and lung homing of newly produced eosinophils.

The biological effects of IL- 25 are mediated by IL- 25 receptor, which is composed of sub-units IL-17RA and IL-17RB. IL-25 is the high affinity ligand for IL-17RB, while IL-17RA shares the common ligand for IL-17A [5, 14]. Polymorphisms in the IL-17RB gene in humans have been linked with asthma susceptibility [15]. In a previous study, we have shown that IL-25 receptor expression on eosinophils is markedly higher in allergic asthmatics compared with atopic non-asthmatic and normal subjects [6]. In addition, we showed that the level of plasma IL-25 significantly increases following allergen inhalation challenge in allergic asthmatics [7]. In humans, IL-25 is produced by structural cells, such as epithelial and endothelial cells, and inflammatory cells, such as eosinophils, basophils and mast cells. IL-25 has been shown to

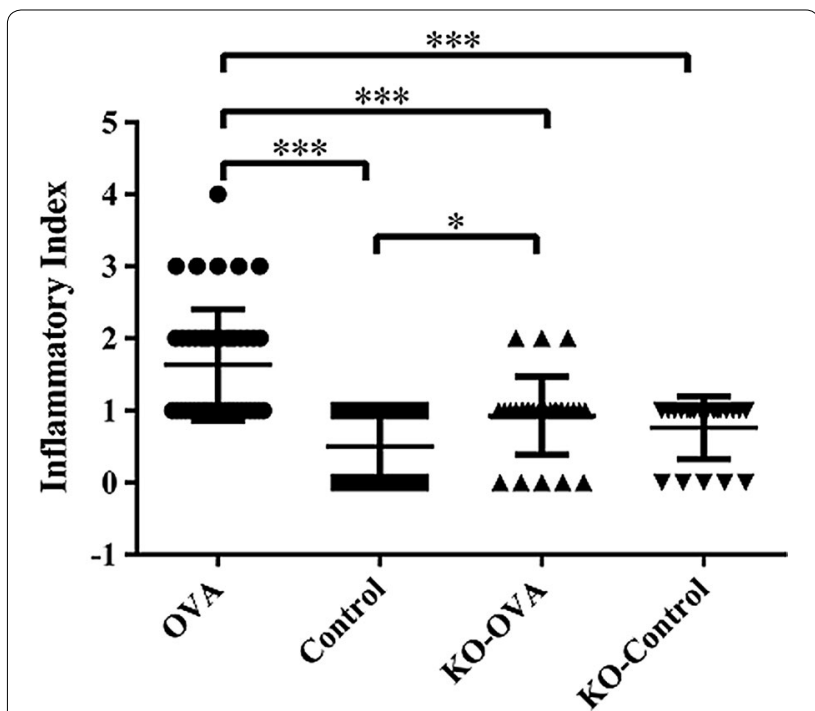

Fig. 3 Inflammatory index of lung tissues from wild type and IL-25 $\mathrm{KO}$ mouse models that were sensitized and challenged with OVA or PBS (control) $\left(^{*} p<0.05\right.$ and ${ }^{* *} p<0.001, n=5$ )

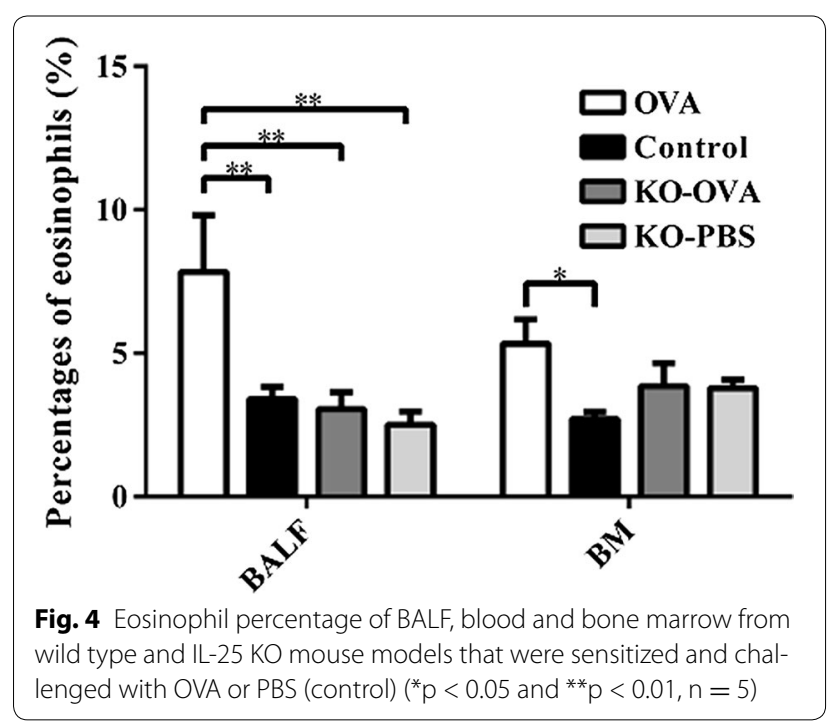

link innate and adaptive immunity by enhancing type- 2 cytokine production, including IL-5 and IL-13 [2].

The current study suggests that IL-25 plays a role in the recruitment of immature eosinophils to the airways in asthma. Our previous research has shown that EoP traffic from the systemic circulation into inflamed tissue sites, the migration orchestrated by locally produced chemokines, such as SDF-1 $\alpha$ [16]. In line with these findings, our current data demonstrate that, although IL-25 did not directly stimulate migrational responses of EoP, pre-exposure to IL-25 enhanced the subsequent migrational response to SDF- $1 \alpha$. As such, it can be postulated that IL-25 may contribute to eosinophilic inflammation 


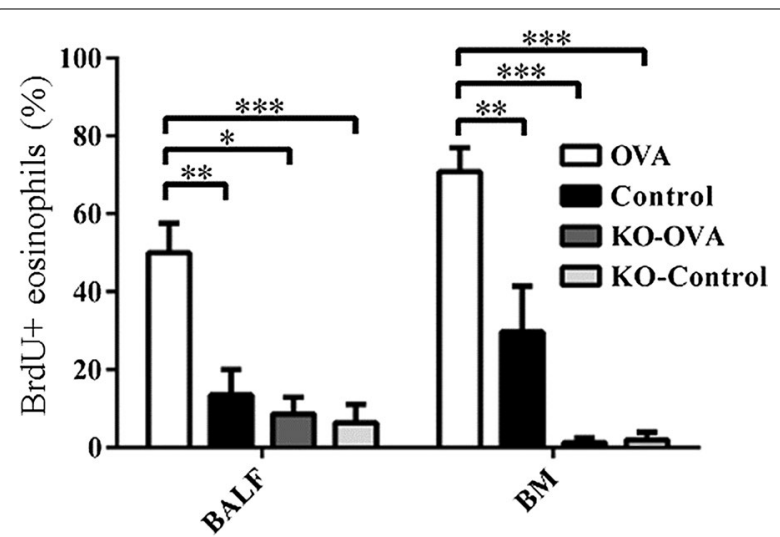

Fig. 5 Percentage of BrdU positive eosinophils of BALF, blood and bone marrow from wild type and IL-25 KO mouse models that were sensitized and challenged with OVA or PBS (control) $\left({ }^{*} p<0.05\right.$, ${ }^{* *} p<0.01$ and ${ }^{* * *} p<0.001, n=5$ )

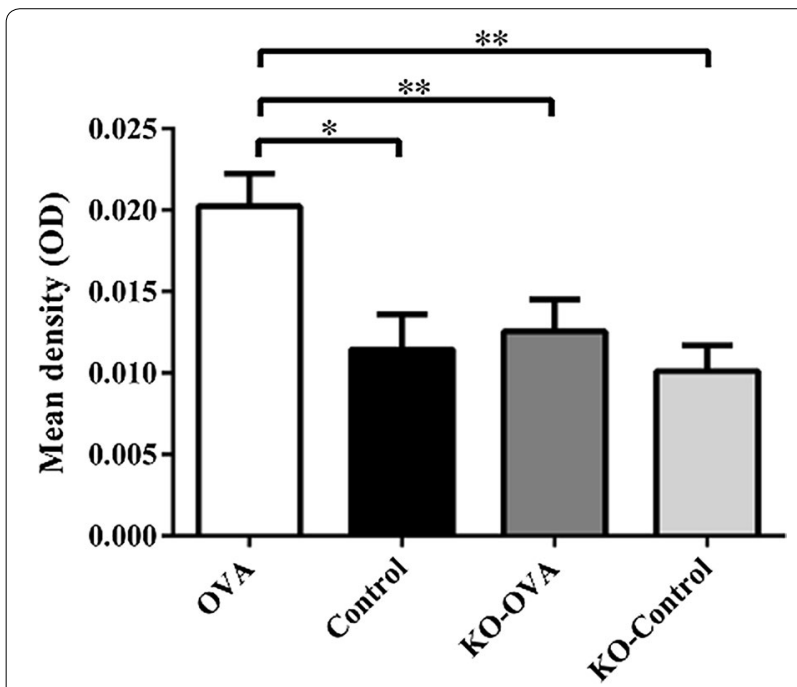

Fig. 6 Expression of BrdU measured by immunohistochemistry wild type and IL-25 KO mouse models that were sensitized and challenged with OVA or PBS (control) $\left(^{*} p<0.05,{ }^{* *} p<0.01\right.$ and ${ }^{* *} p<0.001$,

$n=5)$

observed in the lung following allergen exposure through the priming of migrational responses of immature and mature eosinophils.

We have previously shown a significant increase in $\mathrm{HPC}$ and EoP in the sputum $24 \mathrm{~h}$ post-allergen challenge, which was associated with a significant increase in the expression of receptors for epithelial derived cytokines including TSLP (TSLPR and CD127) and IL-33 (ST2) on HPC and EoP [10]. Furthermore, pre-exposure to TSLP and IL-33 primed the migration of progenitor HPC and this effect was inhibited by blocking antibodies to TSLPR and ST2, respectively, suggesting that lung-homing of
HPC maybe orchestrated by epithelial-derived cytokines, including TSLP and IL-33 [10]. Our current data support the view that the epithelial-derived cytokine IL-25 can prime the migrational response of these cells and promote lung-homing. In contrast to findings with TSLP and IL-33, we show here for the first time that IL-25 can prime the migrational responses of HPC and EoP while the latter cytokines only had effects on HPC [10]. A limitation of the study was that we performed these receptor up-regulation analyses in the blood as opposed to sputum samples as have been described in the above mentioned study. However, our findings in blood-derived eosinophil progenitor cell populations were similar to changes in sputum. Furthermore, the priming experiments with IL-25 were in agreement with the priming experiments performed with TSLP and IL-33 in blood derived cells suggesting similarity in the underlying mechanism.

The pro-inflammatory effects of IL-25 has been well demonstrated in animal models. Exogenous administration of IL-25, or transgenic expression induces type 2 asthma-like inflammation in the airways in mice $[17,18]$. Conversely, anti-IL-25 antibody reduces airway inflammation in animal models of allergic asthma $[19,20]$. In addition, IL-25-deficient mice have significant suppression of the number of eosinophils and the levels of proinflammatory mediators in bronchoalveolar lavage fluids (BALF) [21]. In this current study, OVA challenge of sensitized IL-25-deficient mice not only decreased mobilization of mature eosinophils, but also newly formed eosinophils. In IL-25 KO mice, the attenuation of newly produced eosinophils (BrdU + eosinophils) was observed the airways (BALF) and bone marrow samples suggesting that IL-25 may be involved in the formation of newly produced eosinophils in the bone marrow, as well as in the airways. We acknowledge that by labeling with BrdU, this study only enumerated newly formed eosinophils and not EoP per se. As such, it is unclear as to whether these newly formed eosinophils matured within the bone marrow and migrated to the airways, or if EoP migrated to the airways and differentiated locally within the tissue to mature eosinophils. However, we have previously shown that EoP traffic to the site of inflammation and have the potential of forming eosinophils in situ $[22,23]$ thus supporting the view that the $\mathrm{BrDU}+$ eosinophils arose as a result of local differentiative processes.

\section{Conclusions}

In summary, IL-25 high affinity receptor part (IL-17RB) expression on EoP is increased in the peripheral blood of subjects with asthma after allergen challenge. IL-25 also enhanced the migrational response of eosinophil progenitors. IL-25 knockout mice showed decreased eosinophilic inflammation in the bone marrow and airways. 
Finally, in IL-25 KO mice there was decreased mobilization of newly produced eosinophils after OVA challenge. These results suggest that increases in IL-25 and expression of its receptor on EoP are important in the trafficking of these cells from the bone marrow to the airways during allergen-induced airway responses in asthma and that IL-25 may be a useful drug target to attenuate allergen-induced airway responses.

\section{Additional files}

Additional file 1: Figure S1. Sequential Multi-gating strategy: to identify hemopoietic progenitor cells (HPC: $\left.\mathrm{CD}_{4} 5^{+} \mathrm{CD} 34^{+}\right)$and Eosinophil-lineage committed progenitors (EoP; $\mathrm{CD} 45^{+} \mathrm{CD} 34^{+} \mathrm{CD} 125^{+}$) in blood using FlowJo software on a LSRII. FlowJo plots of specific antibody and isotype control antibody for IL-17RA and IL-17RB on (A) HPC and (B) EoP with a $98 \%$ confidence limit. Absolute cell numbers were calculated by multiplying the $\%$ positive quadrant static (upper right quadrant) with the absolute progenitor cell count and expressed per million white blood cells.

Additional file 2: Figure S2. Histological analysis of lungs. Hematoxylineosin staining of the C57BL/6 in wild type and IL-25 KO mouse models that were sensitized and challenged with OVA or PBS (control).

\section{Abbreviations}

Ag: allergen; $\mathrm{PB}$ : peripheral blood; $F E V_{1}$ : forced expired volume in $1 \mathrm{~s} ; \mathrm{PC}_{20}$ : concentration required to achieve a $20 \%$ decrease in $\mathrm{FEV}_{1}$; EAR: early asthmatic response; LAR: late asthmatic response; ELISA: enzyme-linked immunosorbent assay; HPC: hemopoietic progenitor cell; EoP: eosinophil-lineage committed progenitor cell; SDF-1a: stromal cell derived factor 1a; IL-25(IL-17E): interluekin-25; OVA: ovalbumin; BM: bone marrow; IHC: immunohistochemistry; BrdU: bromodeoxyuridine; KO: knock out; HE: hematoxylin-eosin.

\section{Authors' contributions}

WT participated in the design of the study. WT, SS and AG performed the progenitor cell migration assays as well as flow cytometric acquisition. WD and SG performed FACS analyses and the statistical analysis.WD, JD performed the animal experiment as well as $\mathrm{IHC}$ staining. $\mathrm{KH}$ coordinated the asthma patients study and performed inhalation challenges and lung function testing. GMG, PMO and RS conceived of the study, and participated in its design and coordination and drafted and edited the manuscript. All authors read and approved the final manuscript.

\section{Author details}

1 Division of Respirology, Department of Medicine, McMaster University, Hamilton, ON L6M 1A6, Canada. ${ }^{2}$ Department of Respirology and Critical Medicine, Ruijin Hospital, Shanghai Jiaotong University School of Medicine, Shanghai, China.

\section{Acknowledgements \\ The authors would like to thank all the subjects who volunteered for this study. We thank Sue Beaudin, Tara Scime and Heather Campell for expert technical expertise. We thank for Prof. Xiaohu Wang from Qinhua University Beijin China for providing the IL-25 knockout mice.}

\section{Competing interests}

The authors declare that they have no competing interests.

\section{Availability of data and materials}

We are happy to provide all the raw data to support the information presented in this publication.

\section{Consent for publication}

Not applicable.

\section{Ethics approval and consent to participate}

All subjects gave written informed consent, and this study was approved by the regional Hamilton Health Sciences Research Ethics Board (HIREB \# 12-583).

\section{Funding}

This study was partially supported by grants from the Chinese National Natural Science Foundation (No. 81400012); Interdisciplinary Program of Shanghai Jiao Tong University (Project Number: 2015164); Shanghai Key Discipline for Respiratory Disease (2017ZZ02014). Steven Smith was a recipient of Father Sean O'Sullivan postdoctoral research fellowship award.

\section{Publisher's Note}

Springer Nature remains neutral with regard to jurisdictional claims in published maps and institutional affiliations.

Received: 23 November 2017 Accepted: 1 February 2018

Published online: 13 February 2018

\section{References}

1. Kubo M. Innate and adaptive type 2 immunity in lung allergic inflammation. Immunol Rev. 2017;278(1):162-72.

2. Saenz SA, Taylor BC, Artis D. Welcome to the neighborhood: epithelial cell-derived cytokines license innate and adaptive immune responses at mucosal sites. Immunol Rev. 2008;226:172-90.

3. Cheung PF, Wong CK, Ip WK, Lam CW. IL-25 regulates the expression of adhesion molecules on eosinophils: mechanism of eosinophilia in allergic inflammation. Allergy. 2006;61(7):878-85.

4. Wong CK, Cheung PF, Ip WK, Lam CW. Interleukin-25-induced chemokines and interleukin-6 release from eosinophils is mediated by p38 mitogen-activated protein kinase, c-Jun N-terminal kinase, and nuclear factor-kappaB. Am J Respir Cell Mol Biol. 2005;33(2):186-94.

5. Gaffen SL. Structure and signalling in the IL-17 receptor family. Nat Rev Immunol. 2009;9(8):556-67.

6. Tang W, Smith SG, Beaudin S, Dua B, Howie K, Gauvreau G, et al. IL-25 and IL-25 receptor expression on eosinophils from subjects with allergic asthma. Int Arch Allergy Immunol. 2014;163(1):5-10.

7. Tang W, Smith SG, Salter B, Oliveria JP, Mitchell P, Nusca GM, Howie K, Gauvreau GM, O'Byrne PM, Sehmi R. Allergen-induced increases in interleukin-25 and interleukin-25 receptor expression in mature eosinophils from atopic asthmatics. Int Arch Allergy Immunol. 2016;170(4):234-42.

8. Salter BM, Sehmi R. Hematopoietic processes in eosinophilic asthma. Chest. 2017;152(2):410-6.

9. Cockcroft DW, Davis BE, Boulet LP, Deschesnes F, Gauvreau GM, O'Byrne $P M$, et al. The links between allergen skin test sensitivity, airway responsiveness and airway response to allergen. Allergy. 2005;60(1):56-9.

10. Smith SG, Gugilla A, Mukherjee M, Merim K, Irshad A, Tang W, et al. Thymic stromal lymphopoietin and IL-33 modulate migration of hematopoietic progenitor cells in patients with allergic asthma. J Allergy Clin Immunol. 2015;135(6):1594-602.

11. Johansson AK, Sergejeva SSjöstrand M, et al. Allergen-induced traffic of bone marrow eosinophils, neutrophils and lymphocytes to airways. Eur J Immunol. 2004;34:3135-45.

12. Radinger $M$, Johansson AK, Sitkauskiene $B$, et al. Eotaxin-2 regulates newly produced and $\mathrm{CD}_{3} 4^{+}$airway eosinophils after allergen exposure. J Allergy Clin Immunol. 2004;113(6):1109-16.

13. Massoud AH, Charbonnier LM, Lopez D, et al. An asthma-associated IL4R variant exacerbates airway inflammation by promoting conversion of regulatory T cells to TH17-like cells. Nat Med. 2016;22(9):1013-22.

14. Chang SH, Dong C. Signaling of interleukin-17 family cytokines in immunity and inflammation. Cell Signal. 2011;23(7):1069-75.

15. Jung JS, Park BL, Cheong HS, Bae JS, Kim JH, Chang HS, et al. Association of IL-17RB gene polymorphism with asthma. Chest. 2009;135(5):1173-80.

16. Dorman SC, Babirad I, Post J, et al. Progenitor egress from the bone marrow after allergen challenge: role of stromal cell-derived factor 1alpha and eotaxin. J Allergy Clin Immunol. 2005;115(3):501-7. 
17. Fort MM, Cheung J, Yen D, Li J, Zurawski SM, Lo S, et al. IL-25 induces $\mathrm{IL}-4, \mathrm{IL}-5$, and IL-13 and Th2-associated pathologies in vivo. Immunity. 2001;15(6):985-95.

18. Hurst SD, Muchamuel T, Gorman DM, Gilbert JM, Clifford T, Kwan S, et al. New IL-17 family members promote Th1 or Th2 responses in the lung: in vivo function of the novel cytokine IL-25. J Immunol. 2002;169(1):443-53.

19. Ballantyne SJ, Barlow JL, Jolin HE, Nath P, Williams AS, Chung KF, et al. Blocking IL-25 prevents airway hyperresponsiveness in allergic asthma. J Allergy Clin Immunol. 2007;120(6):1324-31.

20. Angkasekwinai $\mathrm{P}$, Park $\mathrm{H}$, Wang $\mathrm{YH}$, Wang $\mathrm{YH}$, Chang $\mathrm{SH}$, Corry DB, et al. Interleukin 25 promotes the initiation of proallergic type 2 responses. J Exp Med. 2007;204(7):1509-17.
21. Suzukawa M, Morita H, Nambu A, et al. Epithelial cell-derived IL-25, but not Th17 cell-derived IL-17 or IL-17F, is crucial for murine asthma. J Immunol. 2012;189(7):3641-52.

22. Dorman SC, Efthimiadis A, Babirad I, Watson RM, Denburg JA, Hargreave FE, O'Byrne PM, Sehmi R. SputumCD34+IL-5Ra+ cells increase after allergen: evidence for in situ eosinophilopoieisis. Am J Respir Crit Care Med. 2004;169:573-7.

23. Southam DS, Widmer N, Ellis R, Hirota J, Inman MD, Sehmi R. Increased eosinophil-lineage committed progenitors in thelung of allergen challenged mice. J Allergy Clin Immunol. 2005;115:95-102.

\section{Submit your next manuscript to BioMed Central and we will help you at every step:}

- We accept pre-submission inquiries

- Our selector tool helps you to find the most relevant journal

- We provide round the clock customer support

- Convenient online submission

- Thorough peer review

- Inclusion in PubMed and all major indexing services

- Maximum visibility for your research

Submit your manuscript at www.biomedcentral com/submit 